\title{
Optimization of ultrasound-assisted extraction of phenolic compounds from jussara (Euterpe edulis M.) and blueberry (Vaccinium myrtillus) fruits
}

\author{
Juliana de Cássia Gomes ROCHA ${ }^{1 *}$, Fernanda Ramalho PROCÓPIO ${ }^{1}$, Adriana Corrêa MENDONÇA, \\ Luciana Marques VIEIRA ${ }^{1}$, Ítalo Tuler PERRONE ${ }^{1}$, Frederico Augusto Ribeiro de BARROS ${ }^{1}$, \\ Paulo Cesar STRINGHETA ${ }^{1}$
}

\begin{abstract}
This study was aimed at optimizing the ultrasound-assisted extraction (UAE) of phenolic compounds from jussara and blueberry fruits using the response surface methodology (RSM). UAE was found to be more efficient to extract phenolic compounds from both fruits than the conventional extraction. The optimum extraction conditions for the jussara fruits were: extraction time between 30 and $62 \mathrm{~min}$ for total anthocyanins and total phenolics, fruit:solvent ratio of $10 \%$ and $6 \%(\mathrm{w} / \mathrm{v})$ for total anthocyanins and total phenolics, respectively. The ethanol concentration was non-significant ( $p>0.05)$. Acidified water was found to be an extracting solvent as efficient as ethanol in the extraction of phenolic compounds from jussara fruits. The optimum extraction conditions for blueberry anthocyanins were: ethanol concentration between $20-70 \%$ vol, and fruit: solvent ratio greater than $20 \%$ $(\mathrm{w} / \mathrm{v})$ within the range studied. The extraction time was not significant $(\mathrm{p}>0.05)$. For total phenolic content: the concentration of ethanol was between $40-80 \%$, and fruit: solvent ratio greater than $20 \%(\mathrm{w} / \mathrm{v})$ and extraction time over 50 minutes. It was possible to adjust the mathematical model for the coordinates $\mathrm{a}^{\star}$ (verde vs vermelho) and $\mathrm{C}^{\star}$ (color saturation) of the jussara extracts.

Keywords: optimization; ultrasound-assisted extraction; response surface methodology; phenolic compounds.

Practical Application: The ultrasound-assisted extraction is an alternative to conventional extraction methods because it may improve the mass transfer, reducing the extraction time and the solvent use. Thus, our study aimed to compare the phenolic extraction efficiency between the conventional and the ultrasound-assisted methods as well as to optimize the ultrasound-assisted extraction parameters using the response surface methodology. The main findings were that the ultrasound-assisted extraction was more efficient than the conventional extraction of phenolic compounds from both fruits. The acidified water was as efficient as ethanol in the extraction of phenolic compounds from jussara fruits.
\end{abstract}

\section{Introduction}

Jussara (Euterpe edulis M.) is a palm tree native to Brazilian Atlantic Forest. Its fruit is rounded and contains a sole seed covered by a purple and thin pulp. Although jussara is broadly found in the Atlantic Forest, its fruits are less consumed in relation to the açaí fruits (Euterpe oleracea) from Amazon Rainforest. The major anthocyanins of the jussara fruits; cyanidin-3-glucoside and cyanidin-3-rutinoside, are identical to those found in the açai fruits (Brito et al., 2007; Borges et al., 2011; Vieira et al., 2013).

Blueberry (Vaccinium myrtillus) is a native fruit from the northern hemisphere that is rich in phenolic compounds, such as anthocyanins. The main anthocyanins occurring in blueberry fruits are glycosides of cyanidin, delphinidin, malvidin, petunidin and peonidin, but only cyanidin is common to blueberry and jussara fruits (Payne, 2005; Routray \& Orsat, 2011; Paes et al., 2014). Although blueberry is not widely cultivated in Brazil, this fruit presents great potential of production throughout the year due to the tropical climate (Pertuzatti et al., 2012, 2014).

Bioactive compounds have been isolated from vegetal tissues by extraction with organic solvents combined with stirring and/or heating. A commonly used method for extracting anthocyanins and other phenolic compounds, for example, is by macerating the crude plant with a solvent (ethanol, methanol or acetone:water mixtures) containing dilute concentrations of hydrochloric acid $(<1 \%)$ for short or long periods of time (Rodriguez-Saona \& Wrolstad, 2001; Kahkonen et al., 2001). Nevertheless, conventional extraction methods are time-consuming, require large volumes of solvents, and may provoke degradation of certain bioactive substances (Castro \& García-Ayuso, 1998; Aspé \& Fernández, 2011; Roseiro et al., 2013; Machado et al., 2014).

"Green" separation technologies have emerged as alternative methods for the organic solvent-based extraction due to their reduced need for solvents, and shorter time of process. Extraction methods involving ultrasound, microwave, enzymes, and supercritical $\mathrm{CO}_{2}$ are among these emergent separation technologies (Ivanovic et al., 2014). Specifically, the ultrasound-assisted extraction (UAE) can improve mass transfer, thereby shortening the time of extraction and reducing the consumption of solvents in comparison with conventional extraction methods (Vilkhu et al., 2008; Rastogi, 2011; Vieira et al., 2013). 
Assessing the main factors influencing on the process conditions is vital to increase the extraction efficiency of any bioactive compound (Pompeu et al., 2009; Borges et al., 2011). Hence, the objective of this study was to perform a comparison between the conventional and the ultrasound-assisted methods in terms of extraction efficiency of phenolic compounds from jussara and blueberry fruits, and an optimization of the parameters (ethanol concentration, extraction time, and fruit to solvent ratio) of the ultrasound-assisted extraction using the response surface methodology.

\section{Materials and methods}

\subsection{Reagents and samples}

Jussara (Euterpe edulis Mart.) fruits were collected in the rural area of Viçosa, Minas Gerais, Brazil. Blueberry (Vaccinium myrtillus) fruits were collected in Barbacena, Minas Gerais, Brazil. Both fruits were harvested at their physiological maturity, with total soluble solids content of $11.0 \pm 1.7^{\circ} \mathrm{Brix}$ for blueberry fruits and $8.5 \pm 1.9^{\circ}$ Brix for jussara fruits, between 2014 and 2015. Folin-Ciocalteu (FC) reagent and sodium carbonate were purchased from Sigma-Aldrich (St. Louis, MO, USA). Other analytical grade reagents were ethanol (Vetec Fine Chemicals, Ltd., Rio de Janeiro, Brazil), gallic acid (Analyticals CarloErba) and hydrochloric acid (Synth, São Paulo, Brazil).

\subsection{Ultrasound-assisted extraction}

Blueberry and jussara fruits were initially sanitized and crushed in the mixer, while the jussara fruit was added water at $40^{\circ} \mathrm{C}\left( \pm 5^{\circ} \mathrm{C}\right)$, allowed to stand for 20 minutes, after which the water was drained and the fruits macerated for the removal of the stone. The triturated blueberry fruits and the macerated jussara fruits were weighed, and an ethanolic solution was added, then acidified this solution $(\mathrm{pH} 2.0 \pm 0.1)$ with hydrochloric acid. The ultrasound-assisted extraction was performed on an ultrasonic bath (Ultracleaner 1400A, Unique, Brazil) operating at $40 \mathrm{kHz}$ and temperature of $40^{\circ} \mathrm{C}$. The resulting extracts were vacuum-filtered using Whatman $\mathrm{N}^{\circ} .1$ filter paper, and quantitatively transferred to a volumetric flask. The extracts were stored in amber bottles under refrigeration $\left(5^{\circ} \mathrm{C} \pm 1\right)$ for further analysis.

\subsection{Comparative assessment of extraction efficiency}

A particular comparative study between the ultrasound-assisted extraction and the conventional extraction was performed in order to assess the influence of ultrasound on the extraction efficiency of phenolic compounds from the blueberry and jussara fruits. The solvents used in the comparison were $70 \%$ $(\mathrm{v} / \mathrm{v})$ ethanol solution and pure water, both previously acidified to $\mathrm{pH}=2$ with hydrochloric acid. The extracts from both methods were characterized with relation to total anthocyanin content, total phenolics content, and colorimetric coordinates, as described in sections 2.7 to 2.9 .

\subsection{Conventional extraction}

Jussara and blueberry extracts were obtained using 70\% (v/v) ethanol solution or pure water and stored under refrigeration $\left(5 \pm 1{ }^{\circ} \mathrm{C}\right)$ for 24 hours. The fruit to solvent proportion was $1: 10(\mathrm{w} / \mathrm{v})$ in all cases. The extracts were vacuum-filtered using Whatman filter No. 1 paper, quantitatively transferred to volumetric flask, and stored in amber bottles under refrigeration $\left(5 \pm 1{ }^{\circ} \mathrm{C}\right)$ prior to analyzing.

\subsection{Ultrasound-assisted extraction}

Jussara and blueberry extracts were obtained by adding the fruits to a $70 \%(\mathrm{v} / \mathrm{v})$ ethanol solution or pure water and ultrasound treatment for $60 \mathrm{~min}$. The subsequent procedures were the same as those described in section 2.2.

\subsection{Optimization of ultrasound-assisted extraction}

The ultrasound-assisted extraction process was optimized using the response surface methodology based on a central composite design (CCD) with three factors. The CCD consisted of four experiments at the factorial points (combinations between the -1 and +1 levels), four experiments at the axial points (levels $\pm \alpha$ ), and five experiments at the central points (Teófilo \& Ferreira, 2006). The extraction process for each fruit was optimized, thus resulting in a total of 19 experiments for each CCD with 5 repetitions at the central point. The independent variables $(\mathrm{X})$ and their respective levels were: ultrasonic extraction time of 5-62 min, ethanol concentration of $1-94 \%(\mathrm{v} / \mathrm{v})$, and fruit to solvent proportion of $3-25 \%(\mathrm{w} / \mathrm{v})$. Total anthocyanins content, total phenolics content, and colorimetric coordinates $\left(L^{*}, a^{*}, b^{*}, C^{*}\right.$ and $\left.h^{*}\right)$ were selected as the experimental responses $(\mathrm{Y})$. Table 1 summarizes the coded and real values of the independent variables used in the CCDs.

The predicted response was calculated by a second-order polynomial equation. The response $(\mathrm{Y})$ function is divided into linear component, quadratic and interaction components, as expressed in Equation 1:

$Y=\beta o+\sum_{i=1}^{3} \beta i X i+\sum_{i=1}^{3} \beta i i X i^{2}+\sum_{i=1}^{2} \sum_{j=i+1}^{k} \beta i j X i X j+e$

where $\beta_{0}$ is the constant coefficient (intercept), $\beta_{\mathrm{i}}$ is the linear coefficient, $\beta_{\mathrm{ii}}$ is the quadratic coefficient, $\beta_{\mathrm{ij}}$ is the coefficient of interaction, $\mathrm{X}_{\mathrm{i}}$ is the level of the independent variable, and $e$ is the experimental error.

Table 1. Real and coded values of the experimental variables used in the central composite design (CCD).

\begin{tabular}{lcccccc}
\hline \multicolumn{1}{c}{ Experimental variables } & \multirow{2}{*}{ Code } & \multicolumn{5}{c}{ Coded levels } \\
\cline { 3 - 7 } & & 5 & -1 & 0 & +1 & $+\alpha$ \\
\hline Time (min) & $\mathrm{X}_{1}$ & 1 & 20 & 33.0 & 50 & 62 \\
Ethanol concentration (vol.\%) & $\mathrm{X}_{2}$ & 3 & 7 & 13.5 & 75 & 20 \\
Fruit:solvent ratio $(\%, \mathrm{~m} / \mathrm{v})$ & $\mathrm{X}_{3}$ & 3.5 & 25 \\
\hline
\end{tabular}




\subsection{Total anthocyanins determinations}

The total anthocyanins content of extracts was determined by following the methodology described by Lees \& Francis, (1972). The total anthocyanin content was expressed in $\mathrm{mg}$ per $100 \mathrm{~g}$ of fruit.

\subsection{Total phenolics determinations}

The total phenolic content was quantified according to the methodology described by Singleton \& Joseph (1965). Measurements of absorbance were performed at wavelength of $760 \mathrm{~nm}$ on a UV/VIS-1601 PC spectrophotometer (Shimadzu). Gallic acid was used to build analytical curves and curve and total phenolic contents were expressed in mg of gallic acid equivalent (GAE) per $100 \mathrm{~g}$ of fruit (mg GAE100 $\mathrm{g}^{-1}$ ).

\subsection{Colorimetric coordinates}

Color measurements were performed on a ColorQuest XE colorimeter (Hunter Lab, Reston, USA) by directly reading the coordinates $\mathrm{L}^{*}$ (lightness), $\mathrm{a}^{*}$ (red intensity vs. green) and $b^{*}$ (yellow intensity vs. Blue). The parameters hue $\left(h^{*}\right)$ and saturation $\left(\mathrm{C}^{\star}\right)$ were calculated from the $\mathrm{a}^{\star}$ and $\mathrm{b}^{\star}$ values, as given in Equation 2 and Equation 3, respectively.

$h^{*}=\arctan \left(\frac{b^{*}}{a^{*}}\right)$

$c^{*}=\sqrt{a^{* 2}+b^{* 2}}$

\subsection{Statistical analysis}

Data obtained in the comparative study of extraction efficiency were subjected to analysis of variance (ANOVA) and the mean values were compared at confidence level of $95 \%$ $(p<0.05)$ using the Tukey test. The statistical software used was the SAS, Statistical Analysis System, 9.1 version, licensed to the Federal University of Viçosa. Data from the optimization experiments were analyzed using the Statistica 7.0 software, 7.0 version (Tulsa, USA), and the regression coefficients were obtained by multiple linear regression (MLR).

\section{Results and discussion}

\subsection{Comparative analysis of extraction efficiency}

Table 2 shows results of efficiency for the ultrasound-assisted extraction and the conventional extraction performed with 70 vol.\% ethanol solution and pure water. It can be observed that there were no significant differences $(p>0.05)$ between the analyzed parameters for both extraction methods using the same solvent, for both fruits, except for the total anthocyanin content of the jussara extract obtained with ethanol solution, and the colorimetric coordinates $\left(\mathrm{L}^{*}, \mathrm{C}^{*}\right.$, and $\left.\mathrm{h}^{*}\right)$ of the blueberry extract $(\mathrm{p}<0.05)$. This suggests that phenolic compounds can be extracted from jussara and blueberry fruits rapidly using ultrasound-assisted extraction rather than the conventional extraction. Routray \& Orsat (2014) also reported a more efficient extraction of phenolic compounds from blueberry leaves using microwave in comparison with the extraction performed for $24 \mathrm{~h}$ at room temperature.

It is worth pointing out that, for both extraction methods, the same extraction efficiency of anthocyanins and phenolics from jussara fruits was achieved using either water or ethanol solution as the extracting solvent $(p>0.05)$. This reveals that anthocyanins and phenolic compounds can be extracted from jussara fruits from a cheap and broadly accessible solvent, which is likewise safe to humans and to the environment. Vieira et al. (2013) found a higher yield for the ultrasound-assisted extraction of jussara pulp carried out with water acidified with citric acid $(\mathrm{pH}=3.0)$ rather than with ethanol solutions 30-90 vol.\%. However, the ethanolic solutions (30-70\%) imparted greater total anthocyanins and phenolics contents to the extracts in contrast to the results shown in Table 2. Ethanol solution 70 vol.\% was found to be more efficient than water in relation to the extraction of anthocyanins and phenolics from the blueberry fruits. Pompeu et al. (2009) showed that the use of ethanol solutions 70-80 vol.\% increased the extraction efficiency of phenolics and anthocyanins from açaí (Euterpe oleracea) and increased the antioxidant capacity of the açaí extracts accordingly. In terms of colorimetric coordinates, the highest luminosity $\left(L^{*}\right)(36)$ was observed for the aqueous extract $(p<0.05)$. The $C^{\star}$ and $h^{\star}$ values of the sample obtained with 70 vol.\% ethanol solution and ultrasound were the lowest among those of the other samples $(\mathrm{p}<0.05), 25$ and 18 respectively.

Table 2. Comparative evaluation between the ultrasound-assisted and conventional extractions of phenolic compounds from jussara fruit and blueberry using two different extracting solvents (70 vol.\% ethanol solution and pure water).

\begin{tabular}{|c|c|c|c|c|c|}
\hline \multicolumn{6}{|c|}{ Jussara fruit } \\
\hline Sample & TA & $\mathrm{TP}$ & $\mathrm{L}^{*}$ & $C^{*}$ & $\mathrm{~h}^{*}$ \\
\hline J.C - water & $532 \pm 34 \mathrm{a}$ & $1012 \pm 54 . \mathrm{a}$ & $27.14 \pm 0.10 \mathrm{~b}$ & $3.76 \pm 0.59 b$ & $0.12 \pm 2.23 b$ \\
\hline J.U - water & $612 \pm 48 \mathrm{a}$ & $1063 \pm 78 \mathrm{a}$ & $27.26 \pm 0.12 b$ & $3.30 \pm 0.49 b$ & $-2.97 \pm 3.17 b$ \\
\hline J.C - Et.70\% & $400 \pm 51 b$ & $912 \pm 107 a$ & $28.51 \pm 0.28 \mathrm{a}$ & $12.65 \pm 1.47 \mathrm{a}$ & $11.97 \pm 0.82 \mathrm{a}$ \\
\hline J.U - Et.70\% & $515 \pm 68 \mathrm{a}$ & $992 \pm 95 a$ & $28.49 \pm 0.35 \mathrm{a}$ & $12.45 \pm 1.81 \mathrm{a}$ & $11.71 \pm 1.08 \mathrm{a}$ \\
\hline \multicolumn{6}{|c|}{ Blueberry } \\
\hline Sample & TA & $\mathrm{TP}$ & $\mathrm{L}^{*}$ & $\mathrm{C}^{*}$ & $\mathrm{~h}^{\star}$ \\
\hline B.C - water & $48 \pm 8 \mathrm{~b}$ & $122 \pm 14 b$ & $36.27 \pm 1.52 \mathrm{a}$ & $36.85 \pm 3.12 \mathrm{a}$ & $24.10 \pm 1.34 \mathrm{a}$ \\
\hline B.U - water & $76 \pm 21 b$ & $156 \pm 35 b$ & $33.21 \pm 2.28 \mathrm{~b}$ & $28.80 \pm 6.35 a$ & $20.31 \pm 3.04 \mathrm{a}$ \\
\hline B.C - Et. $70 \%$ & $118 \pm 4 a$ & $355 \pm 14 \mathrm{a}$ & $34.33 \pm 0.18 b$ & $35.35 \pm 0.36 \mathrm{a}$ & $20.92 \pm 0.18 \mathrm{a}$ \\
\hline B.U - Et.70\% & $110 \pm 1 \mathrm{a}$ & $310 \pm 4 \mathrm{a}$ & $31.49 \pm 0.07 \mathrm{~b}$ & $25.17 \pm 0.28 \mathrm{~b}$ & $17.82 \pm 0.09 \mathrm{~b}$ \\
\hline
\end{tabular}

C: conventional extraction. U: ultrasound-assisted extraction Et.70\%: ethanol 70\%. J: Jussara. B: Blueberry. (TA) Total anthocyanins content (mg $\left.100 \mathrm{~g}^{-1}\right)$; (TP) total phenolics content

$\left(\mathrm{mg} \mathrm{GAE} 100 \mathrm{~g}^{-1}\right)$. Mean \pm standard deviation $(\mathrm{n}=3)$. Mean values in the column bearing the same letter are not statistically different $(p>0.05)$ according to the Tukey test. 
Water is thus indicated to be an efficient solvent in the ultrasound-assisted extraction of the jussara fruits, while for the blueberry fruits the use of ethanolic solution $70 \%(\mathrm{v} / \mathrm{v})$ is still recommended in order to accomplish an efficient extraction process.

\subsection{Optimization of ultrasound-assisted extraction}

The results obtained from the 19 randomized experiments for each fruit, are displayed in (Table 3). Among the experiments performed on the jussara fruits, the experiment 7 led to the highest total anthocyanins content (735mg $100 \mathrm{~g}^{-1}, 50 \mathrm{~min}$, ethanol concentration of $75 \mathrm{vol} . \%$, and $7 \%(\mathrm{~m} / \mathrm{v})$ fruit:solvent ratio), followed by the experiments 3 and $11\left(610 \mathrm{mg} 100 \mathrm{~g}^{-1}\right)$. The ethanol concentration used in experiment 11 was 1.25 vol.\%, revealing that the extraction of anthocyanins from the jussara fruits is efficient using either high ethanol concentrations or pure water. This result confirms the comparison of efficiency for the ultrasound-assisted extraction performed with ethanol solution 70 vol.\% and water previously discussed in section 3.1 .

Considering the extraction of phenolics from the jussara fruits, the highest content was observed in the experiment 7 (1429 mg AGE $100 \mathrm{~g}^{-1}, 50 \mathrm{~min}$, ethanol concentration of $75 \mathrm{vol} . \%$,

Table 3. Experimental results for jussara fruits and blueberries obtained by CCD.

\begin{tabular}{|c|c|c|c|c|c|c|c|c|c|c|}
\hline \multirow{2}{*}{ Experiments } & \multicolumn{5}{|c|}{ Extraction conditions } & \multicolumn{5}{|c|}{ Experimental responses } \\
\hline & $\mathrm{X}_{1}$ & $\mathrm{X}_{2}$ & $\mathrm{X}_{3}$ & $\mathrm{TA}$ & $\mathrm{TP}$ & $\mathrm{L}^{*}$ & $a^{*}$ & $b^{*}$ & $\mathrm{C}^{*}$ & $\mathrm{~h}^{*}$ \\
\hline \multicolumn{11}{|c|}{ Jussara } \\
\hline $19 \mathrm{C}$ & 33 & 47.5 & 13.5 & 556 & 1239 & 29 & 13 & 3 & 13 & 12 \\
\hline 2 & 16 & 20 & 20 & 472 & 888 & 28 & 6 & 0.74 & 6 & 7 \\
\hline 8 & 50 & 75 & 20 & 499 & 927 & 28 & 12 & 2 & 12 & 12 \\
\hline 4 & 16 & 75 & 20 & 455 & 919 & 28 & 11 & 2 & 11 & 12 \\
\hline 1 & 16 & 20 & 7.0 & 474 & 997 & 30 & 18 & 5 & 19 & 16 \\
\hline 12 & 33 & 94 & 13.5 & 380 & 960 & 31 & 22 & 7 & 23 & 17 \\
\hline 11 & 33 & 1.25 & 13.5 & 610 & 1142 & 28 & 7 & 0.87 & 7 & 8 \\
\hline 13 & 33 & 47.5 & 2.57 & 544 & 1278 & 34 & 30 & 12 & 33 & 21 \\
\hline $15 \mathrm{C}$ & 33 & 47.5 & 13.5 & 564 & 1165 & 29 & 13 & 3 & 14 & 13 \\
\hline 10 & 62 & 47.5 & 13.5 & 550 & 1170 & 29 & 13 & 3 & 13 & 13 \\
\hline $18 \mathrm{C}$ & 33 & 47.5 & 13.5 & 522 & 1078 & 31 & 21 & 6 & 21 & 17 \\
\hline 9 & 5 & 47.5 & 13.5 & 197 & 518 & 33 & 27 & 10 & 29 & 20 \\
\hline 3 & 16 & 75 & 7.0 & 610 & 1309 & 31 & 22 & 7 & 23 & 17 \\
\hline $17 \mathrm{C}$ & 33 & 47.5 & 13.5 & 448 & 1104 & 29 & 16 & 4 & 17 & 15 \\
\hline 14 & 33 & 47.5 & 24.43 & 460 & 791 & 28 & 10 & 2 & 10 & 11 \\
\hline 6 & 50 & 20 & 20 & 558 & 1094 & 27 & 5 & 0.33 & 5 & 4 \\
\hline 7 & 50 & 75 & 7.0 & 735 & 1429 & 30 & 20 & 6 & 21 & 16 \\
\hline 5 & 50 & 20 & 7.0 & 567 & 1152 & 24 & 15 & 4 & 15 & 14 \\
\hline $16 \mathrm{C}$ & 33 & 47.5 & 13.5 & 529 & 1025 & 29 & 13 & 9 & 15 & 34 \\
\hline \multicolumn{11}{|c|}{ Blueberry } \\
\hline $19 \mathrm{C}$ & 33 & 47.5 & 13.5 & 112 & 281 & 38 & 39 & 18 & 42 & 24 \\
\hline 2 & 16 & 20 & 20 & 101 & 159 & 33 & 28 & 10 & 29 & 20 \\
\hline 8 & 50 & 75 & 20 & 107 & 301 & 34 & 31 & 12 & 34 & 21 \\
\hline 4 & 16 & 75 & 20 & 117 & 263 & 34 & 32 & 13 & 34 & 21 \\
\hline 1 & 16 & 20 & 7.0 & 99 & 254 & 42 & 43 & 23 & 48 & 28 \\
\hline 12 & 33 & 94 & 13.5 & 72 & 235 & 41 & 40 & 12 & 41 & 16 \\
\hline 11 & 33 & 1.25 & 13.5 & 103 & 279 & 34 & 30 & 12 & 32 & 22 \\
\hline 13 & 33 & 47.5 & 2.57 & 98 & 262 & 56 & 35 & -2 & 36 & -4 \\
\hline $15 \mathrm{C}$ & 33 & 47.5 & 13.5 & 107 & 257 & 38 & 39 & 18 & 42 & 24 \\
\hline 10 & 62 & 47.5 & 13.5 & 113 & 315 & 36 & 36 & 16 & 40 & 24 \\
\hline $18 \mathrm{C}$ & 33 & 47.5 & 13.5 & 98 & 291 & 38 & 39 & 18 & 42 & 25 \\
\hline 9 & 5 & 47.5 & 13.5 & 99 & 285 & 38 & 38 & 18 & 42 & 24 \\
\hline 3 & 16 & 75 & 7.0 & 81 & 283 & 45 & 43 & 5 & 43 & 6 \\
\hline $17 \mathrm{C}$ & 33 & 47.5 & 13.5 & 99 & 288 & 38 & 40 & 18 & 43 & 25 \\
\hline 14 & 33 & 47.5 & 24.43 & 115 & 317 & 39 & 40 & 17 & 43 & 23 \\
\hline 6 & 50 & 20 & 20 & 122 & 289 & 31 & 23 & 8 & 24 & 18 \\
\hline 7 & 50 & 75 & 7.0 & 79 & 307 & 45 & 43 & 6 & 43 & 8 \\
\hline 5 & 50 & 20 & 7.0 & 101 & 276 & 42 & 42 & 22 & 48 & 28 \\
\hline $16 \mathrm{C}$ & 33 & 47.5 & 13.5 & 101 & 294 & 38 & 39 & 18 & 43 & 24 \\
\hline
\end{tabular}

$\left(\mathrm{X}_{1}\right)$ : Extraction time, $\left(\mathrm{X}_{2}\right)$ ethanol concentration (vol.\%) and $\left(\mathrm{X}_{3}\right)$ fruit:solvent ratio. (TA) Total anthocyanins content $\left(\mathrm{mg}^{\left.100 \mathrm{~g}^{-1}\right)}\right.$; $(\mathrm{TP})$ total phenolics content $\left(\mathrm{mg} \mathrm{GAE} 100 \mathrm{~g}^{-1}\right)$. C: central point. 
and $7 \%(\mathrm{~m} / \mathrm{v})$ fruit:solvent ratio), followed by experiments 3 and 13, 1309 and $1278 \mathrm{mg}$ AGE $100 \mathrm{~g}^{-1}$, respectively.

The lowest fruit:solvent ratio of $2.57 \%(\mathrm{w} / \mathrm{v})$ was used in the experiment 13 , suggesting that the lower the concentration of fruit, the higher the extraction rate of phenolic compounds. Increasing on solvent proportion reduces the energy needed to separate the molecules, thus leading to a higher mobility of solute molecules to the solvent volume (Cacace \& Mazza 2003; Pompeu et al., 2009). With respect to colorimetric parameters, the experiment 13 resulted in the highest $L^{*}, a^{*}$ and $C^{\star}$ values (33 minutes, 47.5 vol.\% ethanol and $2.57 \%(\mathrm{w} / \mathrm{v})$ fruit). The lowest fruit:solvent ratio led to higher $L^{\star}, a^{\star}$ and $\mathrm{C}^{\star}$ values, thus indicating an increased pure red coloration to the extract. The blueberry extracts obtained from experiments 6, 14 and 4 presented the highest total anthocyanins contents, 122,115 and $117 \mathrm{mg} 100 \mathrm{~g}^{-1}$, respectively. The common variable between these experiments was the fruit:solvent ratio of 20 and $24.43 \%(\mathrm{w} / \mathrm{v})$. Unlike the jussara fruits, the blueberry extracts with highest total anthocyanin content were obtained using large amounts of fruit. In addition, the highest total phenolics contents were observed for experiments 14, 10 and 7, which were 317, 315 and $307 \mathrm{mg}$ AGE $100 \mathrm{~g}^{-1}$, respectively. The parameter in common between these experiments was the extraction time of 33-62 min, indicating that longer extraction times led to higher total phenolic contents in the blueberry extracts. Similar results were described by Zou et al. (2011) when they performed the optimization of the ultrasonic assisted extraction of the mulberry fruits, observed an increase in the concentration of anthocyanins with the increase of extraction time in the ultrasound. The concentration of anthocyanins was maximum between 40 and 100 min of extraction.

The blueberry extract obtained from experiment 13 presented the highest $\mathrm{L}^{*}$ value (56), which involved the lowest fruit:solvent ratio, whereas the lowest $L^{\star}$ value (31) was found in the blueberry extract obtained from experiment 6 . The highest values of coordinates colorimetric $\mathrm{a}^{\star}$ and $\mathrm{C}^{\star}$ were observed for the extracts obtained from experiments 1 and 5, which had the ethanol concentration of $20 \mathrm{vol} . \%$ and the fruit:solvent ratio of $7 \%(\mathrm{w} / \mathrm{v})$ as common parameters. The lowest $\mathrm{h}^{\star}$ value $\left(4^{\circ}\right)$ was related to the experiment 13 , in which the fruit:solvent ratio was $2.57 \%(\mathrm{w} / \mathrm{v})$. This suggests that blueberry extracts display a coloration ranging from red to purple when they are obtained from low amounts of fruit.

Statistical models were validated by analysis of variance and F-test at a confidence level of $95 \%$ to build the response surface graphs depicted in Figures 1, 2 and 3. It may be affirmed that the models are suitable to predict total anthocyanins content and total phenolics content of jussara and blueberry extracts if the insignificant lack-of-fit and the $\mathrm{R}^{2}$-values of the models are taken into account. The effects of the parameters $\mathrm{X}_{1}$ (extraction time), $\mathrm{X}_{2}$ (ethanol concentration) and $\mathrm{X}_{3}$ (fruit:solvent ratio) were further studied by determining the significance of the coefficients according to F-test, and evaluating the $\mathrm{p}$-values. The regression equations Equation 4 and Equation 5 for jussara extracts, and

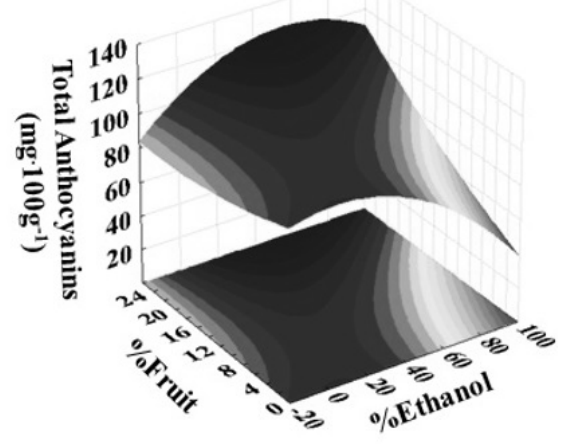

$\mathbf{A}$
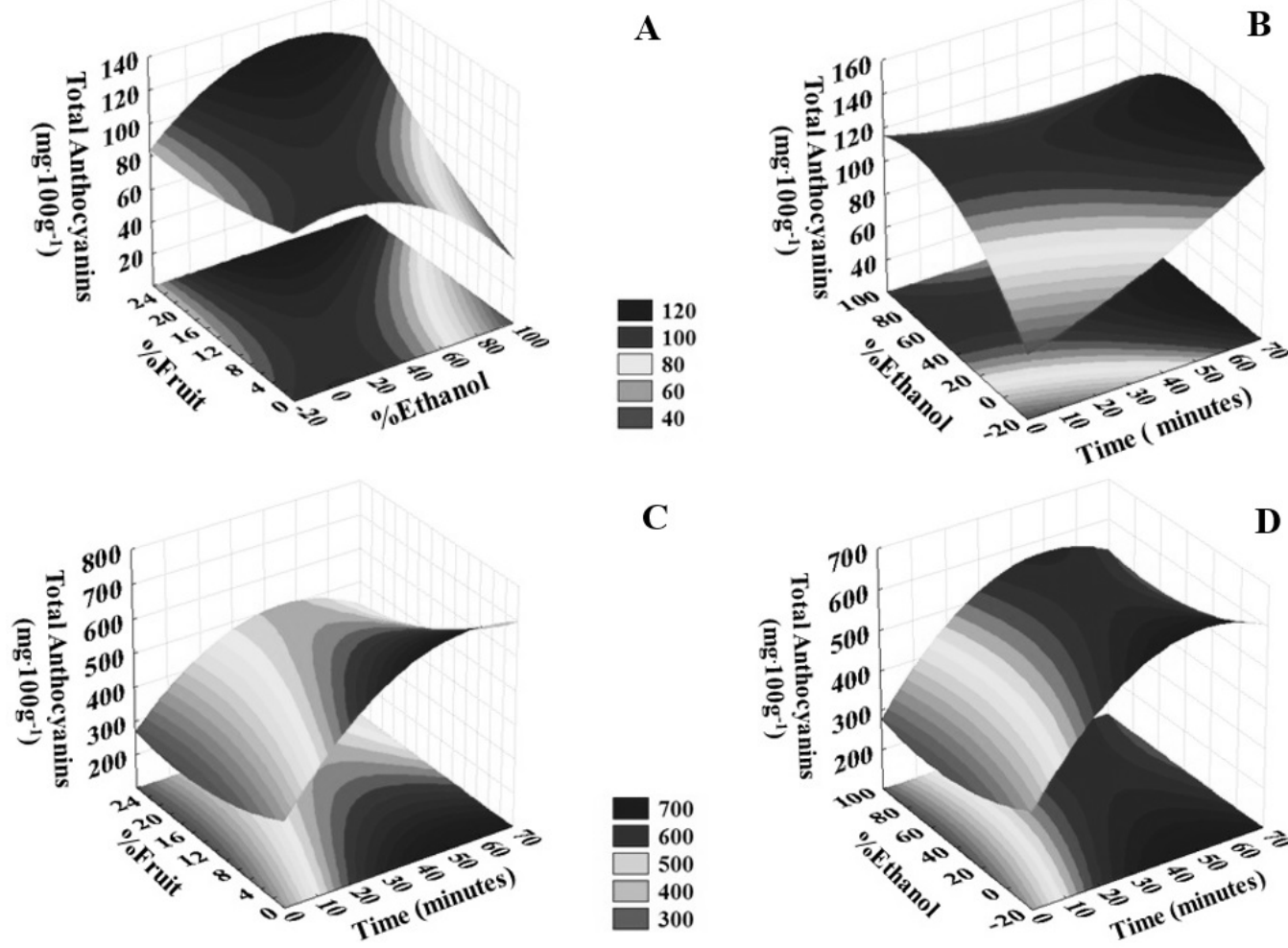

C

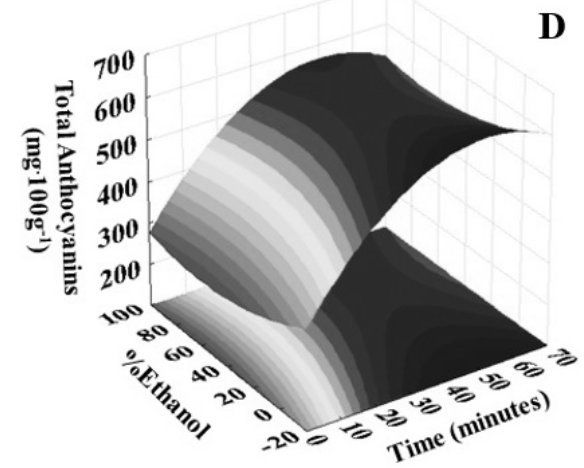

Figure 1. Response surface curves of total anthocyanins content as a function of time (min), ethanol concentration (vol.\%) and fruit content $(\%, w / v)$ for the ultrasound-assisted extraction on blueberry (A and B) and jussara fruit (C and D). 

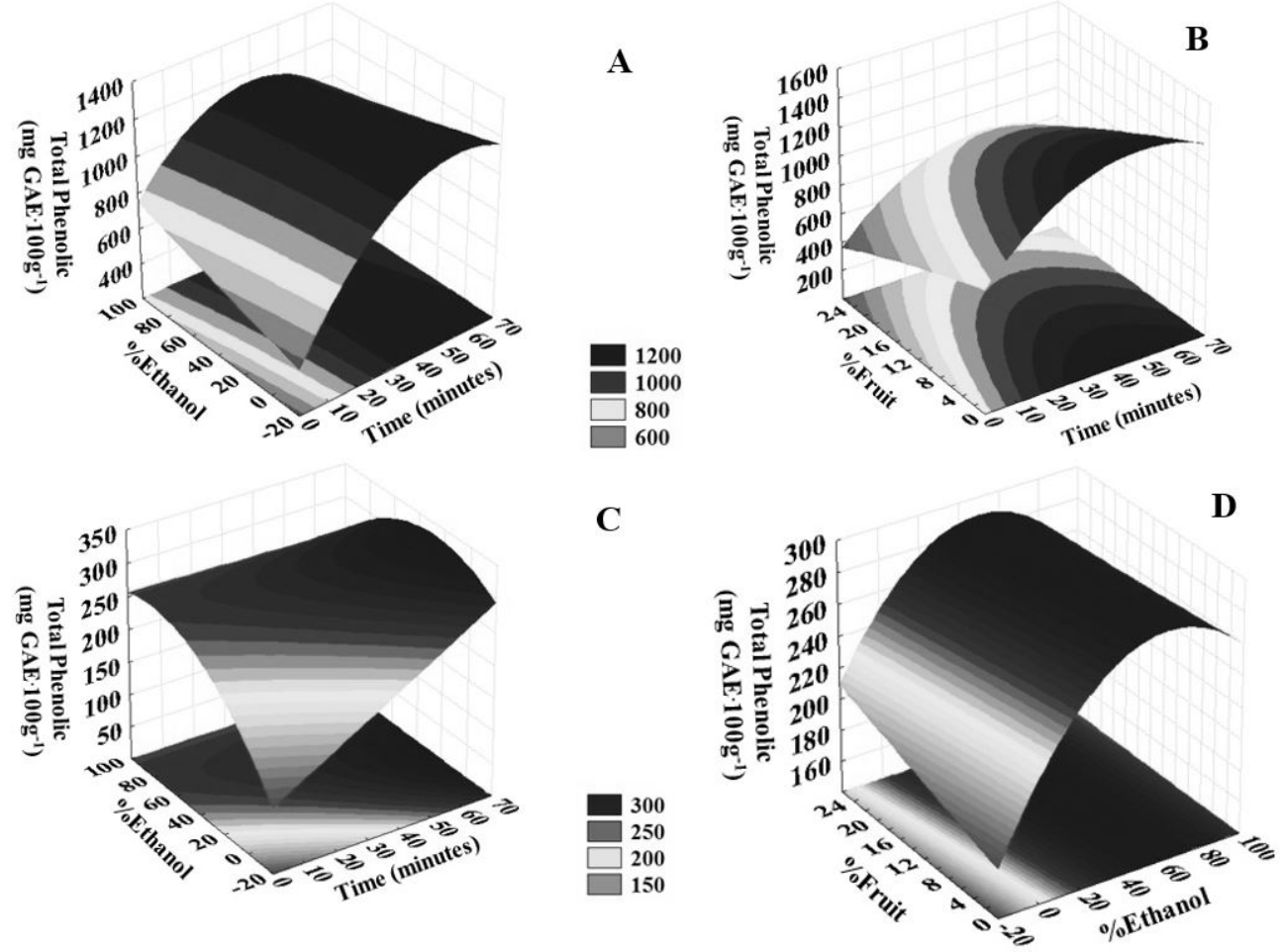

Figure 2. Response surface curves of total phenolics content as a function of time ( $\mathrm{min})$, ethanol concentration (vol.\%) and fruit content (\%, w/v) for the ultrasound-assisted extraction on jussara fruit (A and B) and blueberry (C and D).

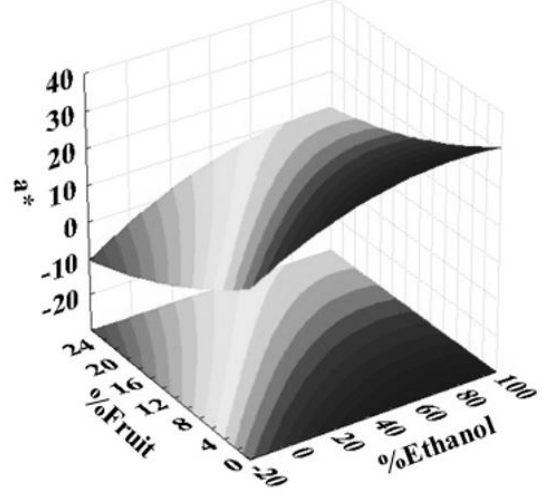

$\mathbf{A}$

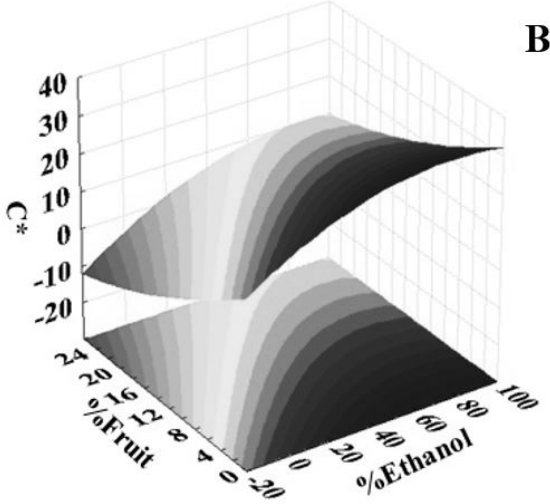

Figure 3. Response surface curves of colorimetric coordinates $\mathrm{a}^{\star}(\mathrm{A})$ and $\mathrm{C}^{\star}(\mathrm{B})$ as a function of time (min), ethanol concentration (vol.\%) and fruit content $(\%, w / v)$ for the ultrasound-assisted extraction on jussara fruits.

Equation 6 and Equation 7 for blueberry extracts) written only with the significant regression terms are given below:

$$
\begin{aligned}
& Y_{1}(T A)=529.26+68.98 X_{1}-34.68 X_{1}^{2}-39.87 X_{3}-47.57 X_{2} X_{3} \\
& Y_{2}(T P)=1118.55+116.16 X_{1}-72.62 X_{1}^{2}-137.56 X_{3}-90.77 X_{2} X_{3} \\
& Y_{3}(T A)=103.15-6.56 X_{2}-5.38 X_{2}^{2}+8.47 X_{3} \\
& Y_{4}(T P)=284.59+19.31 X_{1}-12.52 X_{2}^{2}+15.16 X_{1} X_{3}
\end{aligned}
$$

It can be observed in (Equation 4) and (Equation 5) that the extraction time $\left(\mathrm{X}_{1}\right)$ presented a positive linear correlation with the total anthocyanins content and total phenolics content, meaning that these contents increase linearly over extraction time within the range investigated. On the other hand, the concentration of ethanol $\left(\mathrm{X}_{2}\right)$ did not influence the total anthocyanins content, total phenolics content and colorimetric coordinates significantly $(p>0.05)$. This implies that extraction of phenolic compounds from jussara fruits can be performed either with ethanol solution or water. The fruit:solvent ratio exhibited a negative linear correlation with the total anthocyanins 
content and total phenolics content, indicating that the lower the amount of fruit, the higher the yield of these compounds.

From Equation 6 and Equation 7, it is verified that the ethanol concentration $\left(\mathrm{X}_{2}\right)$ presented a negative linear and quadratic effect, while the fruit:solvent ratio presented a positive linear effect only on the total anthocyanins content $(p>0.05)$. Equation 7 also shows that the extraction time $\left(\mathrm{X}_{1}\right)$ presented a positive linear correlation with the total phenolic content, thus suggesting that the longer the extraction time, the higher the total phenolics yield in the blueberry extracts.

\subsection{Response surface for total anthocyanins content}

Figure 1 displays the response surfaces corresponding to the extraction process for the blueberry (A) and (B) and jussara (C) and (D) fruits. The extraction time did not influence the total anthocyanins content of the blueberry extracts significantly $(p>0.05)$. This can be seen from Figure $1 \mathrm{~B}$, in which the maximum values of anthocyanin content are set along the entire $\mathrm{X}$-axis (0-70 $\mathrm{min})$. The ethanol concentrations and fruit:solvent ratios that yielded the highest total anthocyanins contents were between 20 and 70 vol.\%, and above $20 \%$ of fruit, respectively Figure 1A. Water/ethanol mixtures play an important role in disrupting the hydrogen bonds and hydrophobic interactions between anthocyanins and proteins, and cellulose anthocyanins in the tissues of fruits (Dai \& Mumper, 2010).

Jussara fruits exhibited a behavior fairly different from that of the blueberry fruits with respect to the optimization factors. This confirms that the conditions of the extraction process need to be optimized for each food matrix, thereby justifying the importance of this work. The ethanol concentration presented no significant effect on the total anthocyanin content of the extracts ( $p>0.05$ ), as seen in Figure 1D, in which the maximum values of anthocyanin content are depicted along the $\mathrm{x}$-axis ( 0 to $100 \mathrm{vol} . \%$ ethanol). The highest total anthocyanins contents were obtained for extraction times longer than $30 \mathrm{~min}$ and fruit:solvent ratios lower than 10\% (w/v) Figure 1C.

It was possible to extract anthocyanins from the jussara fruits using only pure water, but for the blueberry fruits it was necessary to use ethanol at concentrations between 20 and $70 \mathrm{vol} . \%$. This finding may be explained by the chemical features of the main anthocyanins present in the jussara and blueberry fruits, cyanidin and malvidin, respectively (Brito et al., 2007; Yousef et al., 2013). Cyanidin presents two hydroxyl group as substituent in its chemical structure, whereas malvidin has a hydroxyl group and two methoxyl groups as a substituent. Barnes et al. (2009) found that malvidin of blueberry fruits displays a larger number of methoxyl groups, which impart a hydrophobic character to this anthocyanin. Thus, malvidin has a stronger affinity for hydrophobic compounds during the extraction and identification by chromatography.

\subsection{Response surface for total phenolics content}

Figure 2 shows response surface graphs for the total phenolic content of the jussara (A) and (B) and blueberry (C) and (D) extracts. The concentration of ethanol did not influence on the extraction of phenolic compounds from jussara fruits significantly
( $p>0.05$ ) Figure 2A. This indicates that the extraction of phenolics from jussara fruits can be attained either with water or ethanol solution. The use of acidified water would provide economical benefits to the extraction process, without needing to remove the solvent prior to using the extract, in addition to the fact that water is nontoxic. Evaporation of the extracting solvent raises the costs of the extraction process and may cause degradation of anthocyanins and phenolic compounds. The combination between extraction time and fruit:solvent ratio that provided the jussara extracts with highest total phenolic contents was 30 to $60 \mathrm{~min}$ and less than $6 \%(\mathrm{w} / \mathrm{v})$, respectively Figure 2B. Earlier studies have shown that highest yields of phenolic compounds are obtained when the ultrasound extraction time is between 45-90 min, which is in close agreement with the extraction times optimized in this study (Borges et al., 2011). Blueberry extracts with the highest total phenolic contents were obtained from the following extraction conditions: ethanol concentration of $40-80$ vol.\% and extraction times longer than $50 \mathrm{~min}$ as shown in Figure 2C. Rodrigues et al. (2015) also observed that ethanol concentrations above of 50 vol.\% and extraction times longer than 60 min resulted in jabuticaba peel extracts with the highest contents of phenolic substances. The fruit:solvent ratio was found to be not statistically significant $(p>0.05)$, as displayed in Figure 2D.

\subsection{Response surface for colorimetric coordinates}

Colorimetric coordinates are usually dependent on the experimental variables used to optimize the extraction process of natural pigments. For the extraction of pigments from the blueberry fruits, all variables were statistically significant, including the lack-of-fit $(p>0.05)$. Thus, it was not possible to adjust a model capable of explaining the variations of the colorimetric coordinates of the blueberry extracts. Figure 3 shows the response surfaces of the colorimetric coordinates $\mathrm{a}^{\star}$ and $\mathrm{C}^{\star}$ for the jussara extracts. None of the experimental variables were significant on the coordinate $h^{\star}(p>0.05)$. For the $L^{\star}$ and $b^{\star}$ coordinates, the lack-of-fit was found to be significant $(p<0.05)$, thus it is not possible to adjust a model for these coordinates. The extraction time was also observed not to be significant $(p>0.05)$ for the coordinates $\mathrm{a}^{\star}$ and $\mathrm{C}^{\star}$, as represented in Figure 3.

Fruit concentrations of up to $8 \%(\mathrm{w} / \mathrm{v})$ and ethanol concentrations higher than $40 \mathrm{vol} \%$ led to extracts with the highest $C^{\star}$ values. As expected, a similar trend is observed in relation to the coordinate $\mathrm{a}^{*}$, which represents the red $v s$. blue coloration, once the $\mathrm{C}^{\star}$ and $\mathrm{a}^{\star}$ coordinates are interrelated. The regression equations (Equation 8 and Equation 9) of the colorimetric coordinates $\mathrm{a}^{\star}$ and $\mathrm{C}^{\star}$ for the jussara and blueberry extracts have been written only with significant regression terms, as expressed below:

$Y_{5}\left(a^{*}\right)=15.22+3.47 X_{2}-5.60 X_{3}$
$Y_{6}\left(C^{*}\right)=16.18+3.67 X_{2}-6.03 X_{3}$

It is noted in Equation 8 and Equation 9 that the ethanol concentration presented a positive linear correlation with $\mathrm{a}^{\star}$ and $\mathrm{C}^{\star}$, indicating that these coordinates increase linearly with increasing ethanol concentration within the range examined. 
Conversely, the fruit:solvent ratio presented a negative correlation with the $\mathrm{a}^{*}$ and $\mathrm{C}^{*}$ values. Therefore, the lower the fruit:solvent ratio, within the range studied, the larger the $\mathrm{a}^{\star}$ and $\mathrm{C}^{\star}$ values. The $\mathrm{R}^{2}$-values for both equations were equal to 0.79 .

\section{Conclusion}

The ultrasound-assisted extraction was confirmed to be a more efficient process than the conventional extraction, once it promoted a more effective extraction of phenolic compounds related to shorter period of time and lower volumes of solvent. Acidified water was an extracting solvent as efficient as ethanol on the extraction of phenolic compounds and anthocyanins from jussara fruits. The response surface methodology was successfully applied to optimize time, ethanol concentration and fruit:solvent ratio involved in the ultrasound-assisted extraction of phenolic compounds and anthocyanins from jussara fruits and blueberries. This study demonstrates that the ultrasound-assisted extraction process needs to be optimized by taking the specific characteristics of each food matrix into account. The dependence of the extraction process on the chemical composition and solubility of fruits deserve further research.

\section{Acknowledgements}

The authors thank CNPq, FAPEMIG and CAPES for financial support.

\section{References}

Aspé, E., \& Fernández, K. (2011). The effect of different extraction techniques on extraction yield, total phenolic, and anti-radical capacity of extracts from Pinus radiata Bark. Industrial Crops and Products, 34(1), 838-844. http://dx.doi.org/10.1016/j.indcrop.2011.02.002.

Barnes, J. S., Nguyen, H. P., Shen, S., \& Schug, K. A. (2009). General method for extraction of blueberry anthocyanins and identification using high performance liquid chromatography-electrospray ionization-ion trap-time of flight-mass spectrometry. Journal of Chromatography. A, 1216(23), 4728-4735. PMid:19414178. http:// dx.doi.org/10.1016/j.chroma.2009.04.032.

Borges, G. D. S. C., Vieira, F. G. K., Copetti, C., Gonzaga, L. V., \& Fett, R. (2011). Optimization of the extraction of flavanols and anthocyanins from the fruit pulp of Euterpe edulis using the response surface methodology. Food Research International, 44(3), 708-715. http:// dx.doi.org/10.1016/j.foodres.2010.12.025.

Brito, E. S., Araújo, M. C. P., Alves, R. E., Carkeet, C., Clevidence, B., \& Novotny, J. (2007). Anthocyanins present in selected tropical fruits: Acerola, jambolão, jussara, and guajiru. Journal of Agricultural and Food Chemistry, 55(23), 9389-9394. PMid:17929888. http://dx.doi. org/10.1021/jf0715020.

Cacace, J. E., \& Mazza, G. (2003). Mass transfer process during extraction of phenolic compounds from milled berries. Journal of Food Engineering, 59(4), 379-389. http://dx.doi.org/10.1016/ S0260-8774(02)00497-1.

Castro, M. D. L., \& García-Ayuso, L. E. (1998). Soxhlet extraction of solid materials: An outdated technique with a promising innovative future. Analytica Chimica Acta, 369(1-2), 1-10. http://dx.doi.org/10.1016/ S0003-2670(98)00233-5.

Dai, J., \& Mumper, R. J. (2010). Plant phenolics: Extraction, analysis and their antioxidant and anticancer properties. Molecules, 15(10), 73137352. PMid:20966876. http://dx.doi.org/10.3390/molecules15107313.
Ivanovic, J., Tadic, V., Dimitrijevic, S., Stamenic, M., Petrovic, S., \& Zizovic, I. (2014). Antioxidant properties of the anthocyanincontaining ultrasonic extract from blackberry cultivar "Ca" canska Bestrna... Industrial Crops and Products, 53, 274-281. http://dx.doi. org/10.1016/j.indcrop.2013.12.048.

Kahkonen, M. P., Hopia, A. I., Heinonen, M., \& Phenolics, B. (2001). Berry Phenolics and Their Antioxidant Activity. Journal of Agricultural and Food Chemistry, 49(8), 4076-4082. PMid:11513713. http:// dx.doi.org/10.1021/jf010152t.

Lees, D., \& Francis, F. (1972). Standardization of pigment analyses in cranberries. HortScience, 7(1), 83-84.

Machado, A. P., Fonseca, D., Pasquel-reátegui, J. L., Fernández, G., \& Martínez, J. (2014). Pressurized liquid extraction of bioactive compounds from blackberry (Rubus fruticosus L. ) residues : a comparison with conventional methods. Food Research International, 77(3), 675-683. http://dx.doi.org/10.1016/j.foodres.2014.12.042.

Paes, J., Dotta, R., Barbero, G. F., \& Martínez, J. (2014). Extraction of phenolic compounds and anthocyanins from blueberry (Vaccinium myrtillus L.) residues using supercritical $\mathrm{CO} 2$ and pressurized liquids. The Journal of Supercritical Fluids, 95, 8-16. http://dx.doi. org/10.1016/j.supflu.2014.07.025.

Payne, T. J. (2005). Formulating with blueberries for health. Cereal Foods World, 50, 262-264.

Pertuzatti, B. P., Barcia, M. T., Jacques, A. C., Vizzotto, M., Godoy, H. T., \& Zambiazi, R. C. (2012). Quantification of several bioactive compounds and antioxidant activities of six cultivars of Brazilian Blueberry. The Natural Products Journale, 2(3), 188-195. http:// dx.doi.org/10.2174/2210315511202030188.

Pertuzatti, P. B., Barcia, M. T., Rodrigues, D., Da Cruz, P. N., HermosínGutiérrez, I., Smith, R., \& Godoy, H. T. (2014). Antioxidant activity of hydrophilic and lipophilic extracts of Brazilian blueberries. Food Chemistry, 164, 81-88. PMid:24996309. http://dx.doi.org/10.1016/j. foodchem.2014.04.114.

Pompeu, D. R., Silva, E. M., \& Rogez, H. (2009). Optimisation of the solvent extraction of phenolic antioxidants from fruits of Euterpe oleracea using Response Surface Methodology. Bioresource Technology, 100(23), 6076-6082. PMid:19581082. http://dx.doi.org/10.1016/j. biortech.2009.03.083.

Rastogi, N. (2011). Opportunities and challenges in application of ultrasound in food processing. Critical Reviews in Food Science and Nutrition, 8(8), 705-722. PMid:21838554. http://dx.doi. org/10.1080/10408391003770583.

Rodrigues, S., Fernandes, F. N., Brito, E. S., Sousa, A. D., \& Narain, N. (2015). Ultrasound extraction of phenolics and anthocyanins from jabuticaba peel. Industrial Crops and Products, 69, 400-407. http:// dx.doi.org/10.1016/j.indcrop.2015.02.059.

Rodriguez-Saona, L. E. \& Wrolstad, R. E. (2001). Extraction, isolation and purification of anthocyanins. In R. E. Wrolstad (Eds.), Current Protocols in Food Analytical Chemistry (chap. F1.1). New York: John Wiley \& Sons. http://dx.doi.org/10.1002/0471142913.faf0101s00.

Roseiro, L. B., Duarte, L. C., Oliveira, D. L., Roque, R., Bernardo-Gil, M. G., Martins, A. I., Sepúlveda, C., Almeida, J., Meireles, M., Gírio, F. M., \& Rauter, A. P. (2013). Supercritical, ultrasound and conventional extracts from carob (Ceratonia siliqua L.) biomass: effect on the phenolic profile and antiproliferative activity. Industrial Crops and Products, 47, 132-138. http://dx.doi.org/10.1016/j.indcrop.2013.02.026.

Routray, W., \& Orsat, V. (2011). Blueberries and their anthocyanins: factors affecting biosynthesis and properties. Comprehensive Reviews in Food Science and Food Safety, 10(6), 303-320. http://dx.doi. org/10.1111/j.1541-4337.2011.00164.x. 
Routray, W., \& Orsat, V. (2014). MAE of phenolic compounds from blueberry leaves and comparison with other extraction methods. Industrial Crops and Products, 58, 36-45. http://dx.doi.org/10.1016/j. indcrop.2014.03.038.

Singleton, V. L., \& Joseph, A. R. (1965). Colorimetry of total phenolics with phosphomolybdic-phosphotungstic acid reagents. American Journal of Enology and Viticulture, (16), 144-158.

Teófilo, R. F., \& Ferreira, M. M. C. (2006). Quimiometria II: Planilhas eletrônicas para cálculus de planejamentos experimentais, um tutorial. Quimica Nova, 29(2), 338-350. http://dx.doi.org/10.1590/ S0100-40422006000200026.

Vieira, G. S., Cavalcanti, R. N., Meireles, M. A. A., \& Hubinger, M. D. (2013). Chemical and economic evaluation of natural antioxidant extracts obtained by ultrasound-assisted and agitated bed extraction from jussara pulp (Euterpe edulis). Journal of Food Engineering, 119(2), 196-204. http://dx.doi.org/10.1016/j.jfoodeng.2013.05.030.
Vilkhu, K., Mawson, R., Simons, L., \& Bates, D. (2008). Applications and opportunities for ultrasound assisted extraction in the food industry - A review. Innovative Food Science \& Emerging Technologies, 9(2), 161-169. http://dx.doi.org/10.1016/j.ifset.2007.04.014.

Yousef, G. G. A. F., Brown, A. F., Funakoshi, Y., Mbeunkui, F., Grace, M. H., Ballington, J. R., Loraine, A., \& Lila, M. A. (2013). Efficient quantification of the health-relevant anthocyanin and phenolic acid profiles in commercial cultivars and breeding selections of blueberries (Vaccinium spp.). Journal of Agricultural and Food Chemistry, 61(20), 4806-4815. PMid:23635035. http://dx.doi.org/10.1021/jf400823s.

Zou, T., Wang, M., Gan, R. Y., \& Ling, W. H. (2011). Optimization of ultrasound-assisted extraction of anthocyanins from mulberry, using response surface methodology. International Journal of Molecular Sciences, 12(5), 3006-3017. PMid:21686165. http://dx.doi. org/10.3390/ijms12053006. 